\title{
Errata
}

doi:10.1093/pan/mpl005

\section{Institutional Context, Cognitive Resources and Party Attachments} Across Democracies

doi:10.1093/pan/mpi025

John D. Huber, Georgia Kernell, and Eduardo L. Leoni

Political Analysis 13(4):365-386.

Table 1 should have appeared as it is set below.

Table 1 Party attachments and contextual variables in 25 countries

\begin{tabular}{|c|c|c|c|c|c|c|c|}
\hline Country & $\begin{array}{l}\text { Proportion } \\
\text { with party } \\
\text { attachments }\end{array}$ & $\begin{array}{c}\text { Social } \\
\text { heterogeneity }\end{array}$ & $\begin{array}{c}\text { Number of } \\
\text { electoral } \\
\text { parties }\end{array}$ & $\begin{array}{l}\text { Effective } \\
\text { number of } \\
\text { legislative } \\
\text { parties }\end{array}$ & $\begin{array}{c}\text { Vote for } \\
\text { candidate }\end{array}$ & $\begin{array}{c}\text { Candidate } \\
\text { control } \\
\text { of ballot }\end{array}$ & $\begin{array}{c}\text { Logged } \\
\text { weighted } \\
\text { party age }\end{array}$ \\
\hline Belgium & 0.85 & 0.77 & 11 & 9.1 & 0 & 0.83 & 3.49 \\
\hline Australia & 0.81 & 0.91 & 6 & 2.6 & 1 & 1 & 4.23 \\
\hline Israel & 0.62 & 0.69 & 11 & 5.61 & 0 & 0 & 3.01 \\
\hline United States & 0.54 & 1.31 & 2 & 2.01 & 2 & 1 & 4.96 \\
\hline Norway & 0.52 & 0.26 & 7 & 4.36 & 0 & 1 & 3.85 \\
\hline New Zealand & 0.51 & 1.21 & 6 & 3.76 & 0.5 & 0.54 & 3.88 \\
\hline Canada & 0.49 & 1.41 & 5 & 2.98 & 2 & 1 & 4.4 \\
\hline Denmark & 0.49 & 0.32 & 10 & 4.66 & 0 & 1 & 3.85 \\
\hline Poland & 0.48 & 0.29 & 6 & 2.95 & 1 & 1 & 1.26 \\
\hline Iceland & 0.48 & 0.27 & 5 & 3.45 & 0 & 0 & 3.79 \\
\hline France & 0.48 & 0.51 & 8 & 2.24 & 2 & 1 & 2.88 \\
\hline Portugal & 0.47 & 0.19 & 5 & 2.58 & 0 & 0 & 3.23 \\
\hline Sweden & 0.46 & 0.29 & 7 & 4.29 & 0 & 1 & 4.33 \\
\hline Britain & 0.46 & 0.82 & 4 & 2.12 & 2 & 1 & 4.67 \\
\hline Czech Republic & 0.44 & 0.98 & 6 & 4.15 & 0 & 1 & 1.39 \\
\hline Bulgaria & 0.42 & 1 & 5 & 2.92 & 0 & 0 & 1.7 \\
\hline Spain & 0.41 & 0.87 & 5 & 3.14 & 0.01 & 0.5 & 2.94 \\
\hline Japan & 0.37 & 0.55 & 6 & 2.94 & 1.2 & 1 & 3.16 \\
\hline Switzerland & 0.36 & 1.14 & 10 & 5.95 & 1.02 & 1 & 4.36 \\
\hline Germany & 0.36 & 0.83 & 5 & 3.3 & 1 & 0.5 & 3.89 \\
\hline Hungary & 0.35 & 0.68 & 7 & 3.45 & 0.91 & 0.46 & 2.29 \\
\hline Lithuania & 0.31 & 0.74 & 5 & 3.27 & 1.01 & 0.5 & 1.89 \\
\hline Netherlands & 0.28 & 0.83 & 9 & 4.79 & 1 & 0 & 3.64 \\
\hline Ireland & 0.26 & 0.28 & 6 & 3.34 & 1 & 1 & 4.25 \\
\hline Slovenia & 0.19 & 0.51 & 6 & 4.38 & 0.04 & 1 & 1.77 \\
\hline
\end{tabular}

Published by Oxford University Press 2006. 